\title{
Price and Service Competition of Dual-Channel Supply Chain with Consumer Returns
}

\author{
Lili Ren, ${ }^{1}$ Yong He, ${ }^{2}$ and Houfei Song ${ }^{2}$ \\ ${ }^{1}$ School of Chemistry and Chemical Engineering, Southeast University, Nanjing 211189, China \\ ${ }^{2}$ School of Economics and Management, Southeast University, Nanjing 210096, China \\ Correspondence should be addressed to Yong He; heyong@126.com
}

Received 26 June 2013; Accepted 21 December 2013; Published 10 February 2014

Academic Editor: Kai Huang

Copyright (C) 2014 Lili Ren et al. This is an open access article distributed under the Creative Commons Attribution License, which permits unrestricted use, distribution, and reproduction in any medium, provided the original work is properly cited.

Products returned by consumers are common in the retail industry and result in additional costs to both the manufacturer and the retailer. This paper proposes dual-channel supply chain models involving consumer returns policies. Also, the price and service competition between retail channel and direct channel is considered in the models. According to the models, we analyze the optimal decisions in both centralized and decentralized scenarios. Then we design a new contract, coordinate the dual-channel supply chain, and enable both the retailer and the manufacturer to be a win-win.

\section{Introduction}

Purchased products that are returned by consumers to retailers are common in the retail industry; for example, Wal-Mart provides full credit for consumer returns under very broad circumstances. Consumer returns policies are part of the competitive strategy used by most of retailers, many of whom commonly provide full refunds without question. In USA, the value of products returned by consumers exceeds $\$ 100$ billion each year, and only about $5 \%$ of them were truly defective $[1,2]$. Related researches show that consumer returns policies are able to strengthen consumer's confidences, stimulate their demands, and improve the market share [3-5]. However, consumer returns policies also bring in some negative impacts on profits, such as increasing cost and malicious return.

The internet has significantly changed the way a consumer consumes as well as the sales model of manufactures and vendors. Nowadays, online shopping became more and more popular, and the electronic channel has become a critical sales channel. Hence, in order to ensure a greater advantage in the market competition, manufacturers and vendors both change the sales model to satisfy the different consumption habits of consumers.

Many papers in dual-channel supply chain address the issue of how manufacturers and retailers could benefit from their own advantages, mainly concentrated on the sales price and service levels. Chen et al. [6] examine how to make the proper decisions of the direct online sales channel together with a retail channel based on the same sales price and the different service levels of dual channel. Dumrongsiri et al. [7] study a dual channel supply chain, which exists in the service and price competition, and analyze how different product, cost, or service characteristics influence the equilibrium behavior of such supply chain. Based on the former research, Hua et al. [8] consider the influence of the delivery time on the price strategy and profits of both manufactures and retailers under coordination of dual channel supply chain which are based on price and delivery time. Cai et al. [9] study the channel choice and coordination of dual channel supply chain. They compare four different channels to illustrate the pros and cons of these channels. Chun et al. [10] analyze optimal channel strategies of a manufacturer when it considers an online store as its new direct channel and discuss some strategic implications of channel strategies from the perspective of consumer heterogeneity and the retail services. Liu et al. [11] study the dual-channel supply chain under information asymmetry. They design two kinds of contracts to coordinate the supply chain and derive the optimal production and the optimal price of dual channel. Chen and Bell [12] bring consumer returns into the dual channel supply chain and study how a firm that faces consumer returns can enhance profit by using different consumer returns policies, 
full-refund, and no-returns, as a device to segment its market into a dual-channel structure. Huang et al. [13] develop a two-period pricing and production decision model in a dualchannel supply chain with demand disruption.

Coordination among suppliers and retailers is a very important strategic issue in supply chain management, and there is a vast literature on coordination contracts in one channel supply chain. For example, Lariviere and Porteus [14] show that the simple wholesale-price-only contract is unable to coordinate the supply chain, and Pasternack [15] shows that a returns policy, when the parameters are properly chosen, can coordinate the supply chain. Recently, some papers put forward several new contracts to coordinate the complex supply chain. For example, He et al. [16] consider a condition in which the stochastic market demand is sensitive to both retail price and sales effort. They show that coordination is achieved by using a properly designed returns policy with a sales rebate and penalty (SRP) contract. Chen and Bell [17] investigate a channel that consists of a manufacturer and a retailer where the retailer simultaneously determines the retail price and order quantity while experiencing customer returns and price dependent stochastic demand. They propose an agreement that includes two buyback prices, one for unsold inventory and one for customer returns, and show that this revised returns policy can achieve perfect supply-chain coordination and lead to a win-win situation. He and Zhao [18] employ a properly designed returns policy between the manufacturer and the retailer, combined with a wholesale-price contract between the raw-material supplier and the manufacturer to coordinate a multiechelon supply chain under supply and demand uncertainty. Cachon [19] and Arshinder et al. [20] provide detailed reviews of this literature. But the coordination in dual-channel supply chain has been largely neglected in the research literature. Only limited studies consider this problem. For example, Cai [21] investigated the influence of channel structures and channel coordination on the supplier, the retailer, and the entire supply chain in a dual-channel supply chain. He shows that a combination of a revenue sharing and a linear price relationship between the price in the retail channel and the price in the direct channel can coordinate the supply chain. Chen et al. [22] examine a manufacturer's pricing strategies in a dual-channel supply chain. They show the conditions under which the manufacturer and the retailer both prefer a dual-channel supply chain and examine the coordination schemes for a dual-channel supply chain and find that a manufacturer's contract with a wholesale price and a price for the direct channel can coordinate the dual-channel supply chain, benefiting the retailer but not the manufacturer.

Different from previous research, in this paper we consider the case of a price and service competition that exists in dual-channel supply chain, besides that, the consumer returns are considered in such supply chain. In decentralized supply chain, we use Stackelberg game and Nash equilibrium to derive the equilibrium solutions; then a new contract is designed to coordinate the dual-channel supply chain.

The rest of this paper is organized as follows. Section 2 introduces model assumptions and problem formulation. Section 3 examines a benchmark case of centralized dualchannel supply chain. In Section 4, we analyze the case of decentralized dual-channel supply chain by using Stackelberg game and Nash equilibrium, respectively. In Section 5, we investigate supply chain behavior and find an optimal contract to coordinate the decentralized supply chain. Section 6 uses numerical studies to illustrate our results. Section 7 presents conclusions, insights, and directions for future research.

\section{Assumptions and Problem Formulation}

In this paper, we assume that both the manufacturer and the retailer provide consumer returns policies and there exists price and service competition between the two channels. Similar to Chen et al. [6], we use the delivery time $t$ to measure the service competition, where $t \in(0,1)$. Also, following several research studies (such as Chen and Bell [12] and Chiang et al. [23]), we assume that consumers have a consumption value $v$, which refers to subjective beliefs about desirable ways to attain personal values, and that $v$ is uniformly distributed $[0,1]$ within the population where $v$ captures individual differences in the value of the product: consumer perceives the product to be worth $v$ when sold by retail channel and $\theta v$ when sold by direct channel. Here, we assume $\theta \in(0,1)$; it indicates that consumer's valuation parameter to the retail channel is greater than the direct channel.

We use subscripts $d$ and $r$ to denote the direct channel and the retail channel, respectively. Then we can derive the consumer's utility $U_{r}=v-p_{r}$ from traditional retail channel or $U_{d}=\theta v-p_{d}-t$ from the direct channel, where $p_{r} \in[0,1]$ and $p_{d} \in[0,1]$ are the sales prices of retail channel and direct channel, respectively.

Usually, if $U_{d} \geq 0$, consumers choose to purchase products from the direct channel; if $U_{r} \geq 0$, consumers choose to purchase products from the retail channel. In this paper, we consider the competition between the direct channel and the retail channel. So, if $U_{d}>U_{r}$, consumers choose to purchase products from the direct channel; on the contrary, if $U_{d}<U_{r}$, consumers choose to purchase products from the retail channel.

Let $c$ be the product cost, let $l$ be the salvage value, and $w$ be the wholesale price. In this paper, we assume $c, l$, and $w$ are constant and less than 1 . The following assumptions are used to formulate the problem.

(a) The products that consumers brought can be returned to the manufacturer who provides full refunds without question. The manufacturer can continue to sell the returned products which have been renewed with small additional costs.

(b) If the products cannot be sold out at the end of sale season, the manufacturer can get salvage value from the unsold products. It is reasonable to assume that $c>l$.

(c) Let $\alpha$ be the return rate in the retail channel and let $\beta$ be the return rate in the direct channel. It is natural to assume that $0 \leq \alpha<1,0 \leq \beta<1$, and $0 \leq \alpha+\beta<1$.

(d) If consumers return the products that were bought from the direct channel, while their utility for the 
retail channel is greater than zero, they will choose to purchase the products from the retail channel. Meanwhile if consumers return the products that were bought from the retail channel, while if their utility for the direct channel is greater than zero, they will choose to purchase the products from the direct channel.

(e) The utility of the consumer for the same kind of product is subject to uniform distribution.

And according to Chen and Bell [12] and Assumption (e), we know the demand for the product is $\int_{p}^{1} d v=1-p$, where $p$ is the sale price. We denote the indifferent values for each channel as $v_{d}=\left(p_{d}+t\right) / \theta$ and $v_{r}=p_{r}$ and the point where the customer is indifferent between the channels as $v_{r d}=\left(p_{r}-\right.$ $\left.p_{d}-t\right) /(1-\theta)$.

When $v_{r}<v_{d}$, we have $v_{d}>v_{r}>v_{r d}$; this implies that no customer will buy from the direct channel and the customer whose reservation price is in the range $\left[v_{r}, 1\right]$ will only purchase a product in the retailer sale channel.

When $v_{r}>v_{d}$, we have $v_{d}<v_{r}<v_{r d}$; this implies that the customer whose reservation price is in the range $\left[v_{r d}, 1\right]$ will purchase from the retailer sale channel, while they will purchase from the direct channel if their reservation price is in the range $\left[v_{d}, v_{r d}\right]$. The customers whose reservation price is in the range $\left[0, v_{d}\right]$ will not buy a product.

Because of the valuation of the customers is uniformly distributed, the demands of the dual-channel can be modeled as follows:

$$
\begin{gathered}
D_{r}\left(p_{r}, p_{d}\right)=1-p_{r}, \quad \text { if } p_{r} \leq \frac{p_{d}+t}{\theta}, \\
D_{d}\left(p_{r}, p_{d}\right)=0, \quad \text { if } p_{r} \geq \frac{p_{d}+t}{\theta} . \\
D_{r}\left(p_{r}, p_{d}\right)=1-\frac{p_{r}-p_{d}-t}{1-\theta}, \\
D_{d}\left(p_{r}, p_{d}\right)=\frac{p_{r}-p_{d}-t}{1-\theta}-\frac{p_{d}+t}{\theta},
\end{gathered}
$$

Hence, from analysis we have the following.

(I) If $p_{r} \leq\left(p_{d}+t\right) / \theta, \alpha D_{r}\left(p_{r}, p_{d}\right)$ consumers will return their products in the retail channel, and, among these consumers, $\left(1-v_{d}\right) /\left(1-v_{r}\right)$ ratio of them will buy from the direct channel since $U_{d} \geq 0$ for these consumers who become the additional demand for the direct channel. The rest, that is, $\left(v_{d}-v_{r}\right) /\left(1-v_{r}\right)$ ratio of $\alpha D_{r}\left(p_{r}, p_{d}\right)$ consumers, have $U_{d}<0$, and they leave the system without buying the product and become the lost demand.

(II) If $p_{r} \geq\left(p_{d}+t\right) / \theta, \beta D_{d}\left(p_{r}, p_{d}\right)$, consumers will return their products in the direct channel, and they are lost demand since $U_{r}<0$ for these consumers in the retail channel and they leave the system without buying the product.

(III) If $p_{r} \geq\left(p_{d}+t\right) / \theta, \alpha D_{r}\left(p_{r}, p_{d}\right)$, consumers will return their products in the retail channel, but these consumers will buy from the direct channel since they have $U_{d} \geq 0$, and these consumers become the additional demand for the direct channel.
Therefore, when $p_{r} \leq\left(p_{d}+t\right) / \theta$, the direct channel only sells the returned products which are returned from the retail channel and renewed with small additional costs. In this case, the direct channel can be recognized as a second market to sell the remanufactured products.

When $p_{r} \geq\left(p_{d}+t\right) / \theta$, the new products can be sold in both channels, but only the direct channel can sell the returned products. This phenomenon is very popular in reality.

\section{The Centralized Dual-Channel Supply Chain}

In this section, we consider a centralized dual-channel supply chain, in which the manufacturer and the retailer are vertically integrated in the traditional channel.

3.1. Scenario $1\left(p_{r} \leq\left(p_{d}+t\right) / \theta\right)$. Under such dual-channel supply chain, the direct channel only sells the returned products. Then the profit of the centralized supply chain $\Pi_{T}$ is

$$
\begin{aligned}
\Pi_{T}= & \max _{p_{r}, p_{d}} p_{r}(1-\alpha)\left(1-p_{r}\right)-c\left(1-p_{r}\right) \\
& +\alpha \frac{1-v_{d}}{1-v_{r}}\left(1-p_{r}\right) p_{d}+\alpha l \frac{v_{d}-v_{r}}{1-v_{r}}\left(1-p_{r}\right) \\
& \text { subject to } p_{r} \leq \frac{p_{d}+t}{\theta} .
\end{aligned}
$$

This optimization leads to the following result.

Proposition 1. Under a centralized dual-channel supply chain with $p_{r} \leq\left(p_{d}+t\right) / \theta$, there is a threshold delivery time $t_{1}^{*}=$ $(\theta(c-\alpha l)-l(1-\alpha)) /(1-\alpha)$ such that, ift $<t_{1}^{*}$, the optimal prices are

$$
\begin{gathered}
p_{d}^{*}=\frac{\theta}{2}\left(1+\frac{c+\alpha t}{1-\alpha+\alpha \theta}\right)-t, \\
p_{r}^{*}=\frac{1}{2}\left(1+\frac{c+\alpha t}{1-\alpha+\alpha \theta}\right) .
\end{gathered}
$$

(Case A1)

If $t \geq t_{1}^{*}$, the optimal prices are

$$
\begin{gathered}
p_{d}^{*}=\frac{\theta-t+l}{2}, \\
p_{r}^{*}=\frac{1}{2}\left(1+\frac{c-\alpha l}{1-\alpha}\right) .
\end{gathered}
$$

The optimal policy is continuous at the threshold $t_{1}^{*}$.

Proof. From (3), we know that $\partial^{2} \Pi_{T} / \partial p_{r} \partial p_{d}=\partial^{2} \Pi_{T} / \partial p_{d} \partial p_{r}$ $=0, \partial^{2} L / \partial p_{r}^{2}=-2(1-\alpha)$, and $\partial^{2} L / \partial p_{d}^{2}=-(2 \alpha / \theta)$. Let $M$ be the Hessian Matrix; then we obtain that

$$
M=\left(\begin{array}{cc}
\frac{\partial^{2} L}{\partial p_{r}^{2}} & \frac{\partial^{2} L}{\partial p_{r} \partial p_{d}} \\
\frac{\partial^{2} L}{\partial p_{r} \partial p_{d}} & \frac{\partial^{2} L}{\partial p_{d}^{2}}
\end{array}\right)
$$


is negative definite matrix. Hence, (3) is a convex optimization problem. In all proofs, we focus on the Lagrangian multipliers and on the orthogonality conditions of the KarushKuhn-Tucker theorem.

Then the Lagrangian and the Karush-Kuhn-Tucker optimality conditions are

$$
\begin{aligned}
& L\left(p_{r}, p_{d}\right)= p_{r}(1-\alpha)\left(1-p_{r}\right)-c\left(1-p_{r}\right) \\
&+\alpha \frac{1-v_{d}}{1-v_{r}}\left(1-p_{r}\right) p_{d}+\alpha l \frac{v_{d}-v_{r}}{1-v_{r}}\left(1-p_{r}\right) \\
&+\lambda\left(\frac{p_{d}+t}{\theta}-p_{r}\right), \\
& \frac{\partial L}{\partial p_{r}}=c+\left(1-2 p_{r}\right)(1-\alpha)-\alpha l-\lambda=0, \\
& \frac{\partial L}{\partial p_{d}}=\frac{\alpha l-2 \alpha p_{d}-t \alpha+\alpha \theta+\lambda}{\theta}=0, \\
& \lambda\left(\frac{p_{d}+t}{\theta}-p_{r}\right)=0 .
\end{aligned}
$$

Since the multiplier can be either zero or positive, we could have two cases to examine.

Case $A 1(\lambda>0)$. The value of $\lambda$ is

$$
\lambda=\frac{-\alpha(t+l-l \alpha-c \theta-\alpha t+l \alpha \theta)}{1-\alpha+\alpha \theta} .
$$

Since the multiplier is positive, we have the necessary condition in this case

$$
t<\frac{\theta(c-\alpha l)-l(1-\alpha)}{1-\alpha}=t_{1}^{*} .
$$

Since the condition is satisfied, the prices in each channel are

$$
\begin{gathered}
p_{d}^{*}=\frac{\theta}{2}\left(1+\frac{c+\alpha t}{1-\alpha+\alpha \theta}\right)-t, \\
p_{r}^{*}=\frac{1}{2}\left(1+\frac{c+\alpha t}{1-\alpha+\alpha \theta}\right) .
\end{gathered}
$$

Case A2 $(\lambda=0)$. The prices in each channel are

$$
\begin{gathered}
p_{d}^{*}=\frac{\theta-t+l}{2}, \\
p_{r}^{*}=\frac{1}{2}\left(1+\frac{c-\alpha l}{1-\alpha}\right) .
\end{gathered}
$$

Because of $p_{r} \leq\left(p_{d}+t\right) / \theta$, we obtain the necessary condition in this case

$$
t>\frac{\theta(c-\alpha l)-l(1-\alpha)}{1-\alpha}=t_{1}^{*} .
$$

Also, it is simple to show that the policy is continuous in $t_{1}^{*}$, by forcing $t=t_{1}^{*}$ in the optimal policy of Case A2.
From Proposition 1, we know that $d p_{d}^{*} / d t<0$ in both Cases A1 and A2; this indicates that the direct sale price is always decreasing in $t$. But $d p_{r}^{*} / d t>0$ in Case Al while $d p_{r}^{*} / d t=0$ in Case A2; this means that the retail sale price is increasing in $t$ when $t<t_{1}^{*}$; however, when $t \geq t_{1}^{*}$, the retail sale price will not be influenced by $t$ anymore.

3.2. Scenario $2\left(p_{r} \geq\left(p_{d}+t\right) / \theta\right)$. In such dual-channel supply chain, the direct channel can sell not only the new products but also the returned products. Then the profit of the centralized supply chain is

$$
\begin{aligned}
\Pi_{T}= & \max _{p_{r}, p_{d}} p_{r}(1-\alpha) D_{r}+p_{d}(1-\beta) D_{d}-c\left(D_{r}+D_{d}\right) \\
& +\alpha p_{d} D_{r}+l \beta D_{d} \\
& \text { subject to } p_{r} \geq \frac{p_{d}+t}{\theta} .
\end{aligned}
$$

From (11), we know that when $p_{r} \geq\left(p_{d}+t\right) / \theta$, taking second partial derivatives with respect to $p_{r}$ and $p_{d}$, the existence condition for a unique optimal solution to $p_{r}$ and $p_{d}$ is $4(1-\theta) / \theta>\beta^{2} /((1-\alpha)(1-\beta))$ or

$$
\theta<\bar{\theta}=1-\frac{\beta^{2}}{4(1-\alpha)(1-\beta)+\beta^{2}} .
$$

$\bar{\theta}$ in (12) is a decreasing function of $\alpha, \beta$. For instance, when $\alpha=\beta=0.3$, we have $\bar{\theta}=0.9561$. So we conclude that optimal prices exist for a broad range of $\theta, \alpha$, and $\beta$.

Proposition 2. Under a centralized dual-channel supply chain with $p_{r} \geq\left(p_{d}+t\right) / \theta$, there is a threshold delivery time $t_{2}^{*}=((1-$ $\alpha)(2 c \theta+2 \beta l-2 c-\beta \theta)+\beta \theta(2 \alpha l-c-\alpha \theta)) /(2(1-\alpha)(1-\beta)-\alpha \beta \theta)$ such that, if $t>t_{2}^{*}$, the optimal prices are

$$
\begin{gathered}
p_{d}^{*}=\frac{\theta}{2}\left(1+\frac{c+\alpha t}{1-\alpha+\alpha \theta}\right)-t, \\
p_{r}^{*}=\frac{1}{2}\left(1+\frac{c+\alpha t}{1-\alpha+\alpha \theta}\right) .
\end{gathered}
$$

(Case B1)

If $t \leq t_{2}^{*}$, the optimal prices are

$$
\begin{aligned}
p_{d}^{*}= & l-(1-\alpha)((2-\beta)[(2 l-\theta)(1-\theta)+(2-\theta) t] \\
& +2 c \theta-2 t-2 c) \\
& \times\left(4(1-\alpha)(1-\beta)(1-\theta)-\beta^{2} \theta\right)^{-1}, \\
p_{r}^{*}=\frac{1}{2}-\left(\left(\alpha \beta-\alpha \beta \theta-\frac{\beta^{2}}{2}\right)(\theta-2 l)\right. & \quad+(1-\theta)(\beta c-2 c+2 \alpha c)+\beta t(\alpha \theta-1+\beta)) \\
& \times\left(4(1-\alpha)(1-\beta)(1-\theta)-\beta^{2} \theta\right)^{-1} .
\end{aligned}
$$

(Case B2)

The optimal policy is continuous at the threshold $t_{2}^{*}$. 
TABLE 1: The Stackelberg equilibriums.

\begin{tabular}{|c|c|c|c|}
\hline & Case C1: $t \leq t_{1}^{S}$ & Case C2: $t_{1}^{S} \leq t \leq t_{2}^{S}$ & Case C3: $t \geq t_{2}^{S}$ \\
\hline$p_{d}^{S}$ & $\frac{1}{2}\left[\frac{M}{(1-\beta)(2-\theta)-\alpha \theta}-t\right]$ & $\frac{(1-\theta+w) \theta}{2-\theta}-t$ & $\frac{c-w+w \alpha-\alpha t+\alpha \theta}{2 \alpha}$ \\
\hline$p_{r}^{S}$ & $\frac{1}{4}\left[2(1-\theta+w)+t+\frac{M}{(1-\beta)(2-\theta)-\alpha \theta}\right]$ & $\frac{1-\theta+w}{2-\theta}$ & $\frac{c-w+w \alpha+\alpha t+\alpha \theta}{2 \alpha \theta}$ \\
\hline
\end{tabular}

$M=(\beta-1-\alpha) \theta^{2}+(1+2 w+\alpha+l \beta-2 c-2 w \alpha-\beta-w \beta) \theta+2 c-2 l \beta$,

$t_{1}^{S}=(2 \theta(1-\theta+w)) /(2-\theta)-M /((1-\beta)(2-\theta)-\alpha \theta)$, and

$t_{2}^{S}=(2 \theta(1+w-\theta)) /(2-\theta)-(c+w \alpha-w+\alpha \theta) / \alpha$.

Proof. The proof is similar to that of Proposition 1 and is omitted.

\section{The Decentralized Dual-Channel Supply Chain}

In this section, we consider a decentralized dual-channel supply chain, in which both the manufacturer and the retailer make their own decisions to maximize their individual profits. For decentralized dual-channel supply chain, the most popular mode is that the manufacturer also sells the new products by direct channel, which will lead to the service and price competition with retailer. Hence, in decentralized supply chain we only consider the scenario of $p_{r} \geq\left(p_{d}+t\right) / \theta$.

Since $p_{r} \geq\left(p_{d}+t\right) / \theta$ in this scenario, $D_{r}$ and $D_{d}$ satisfy (2). The profit of the retailer is

$$
\Pi_{r}=\left(p_{r}-w\right)(1-\alpha) D_{r}
$$

The manufacturer's profit is

$$
\begin{aligned}
\Pi_{d}= & w(1-\alpha) D_{r}-c\left(D_{r}+D_{d}\right)+p_{d}(1-\beta) D_{d} \\
& +\alpha p_{d} D_{r}+l \beta D_{d} .
\end{aligned}
$$

Next, we will obtain the equilibrium solutions by using the Stackelberg game and the Nash equilibrium.

4.1. Stackelberg Game. In reality, decisions usually are taken sequentially; some players decide first and the others respond to these. This may be due to the lack of information of a player about the other. With Stackelberg game, we model the decision process as a sequential. The manufacturer can therefore operate as a Stackelberg leader while the retailer would be the follower. The sequence of the events is as follows.

(a) The manufacturer, as the Stackelberg leader, owns the complete information. He determines the direct sale price $p_{d}$ and the delivery lead time $t$ first based on the retailer's response.

(b) The retailer, knowing the supplier's decisions, determines his retail price.

(c) The selling season starts and demand is observed.

Hence, we know that such a Stackelberg game will lie on the following two-stage process: first, we can obtain the retailer's best response function from the retailer's maximization problem; then, the manufacturer maximizes their profit based on the retailer's best response function.

Proposition 3. Under the decentralized dual-channel supply chain, the Stackelberg equilibrium prices $\left(p_{d}^{S}, p_{r}^{S}\right)$ can be shown in Table 1.

From Proposition 3, we know that there are two threshold delivery times $t_{1}^{S}$ and $t_{2}^{S}$, and the Stackelberg equilibrium prices are continuous at the thresholds $t_{1}^{S}$ and $t_{2}^{S}$.

Proof. First, we derive the retailer's best response to manufacturer's decisions. The profit of the retailer is

$$
\begin{aligned}
\Pi_{r}= & \max _{p_{r}}\left(p_{r}-w\right)(1-\alpha)\left(1-\frac{p_{r}-p_{d}-t}{1-\theta}\right) \\
& \text { s.t. } p_{r} \geq \frac{p_{d}+t}{\theta} .
\end{aligned}
$$

Using the Lagrangian duality, we can easily get

$$
\begin{gathered}
p_{r}^{S}=\frac{1-\theta+p_{d}+w+t}{2}, \quad p_{d} \leq \frac{(1-\theta+w) \theta}{2-\theta}-t, \\
p_{r}^{s}=\frac{p_{d}+t}{\theta}, \quad p_{d} \geq \frac{(1-\theta+w) \theta}{2-\theta}-t .
\end{gathered}
$$

Hence, the profit of the manufacturer will be divided into two scenarios:

(1)

$$
\begin{aligned}
\Pi_{d}= & \max _{p_{d}}\left[w(1-\alpha)+\alpha p_{d}\right]\left[\frac{1}{2}+\frac{p_{d}+t-w}{2(1-\theta)}\right] \\
& -c\left(1-\frac{p_{d}+t}{\theta}\right) \\
& +\left[p_{d}(1-\beta)+l \beta\right]\left[\frac{1}{2}-\frac{p_{d}+t-w}{2(1-\theta)}-\frac{p_{d}+t}{\theta}\right] \\
& \text { s.t. } p_{d} \leq \frac{(1-\theta+w) \theta}{2-\theta}-t ;
\end{aligned}
$$

(2)

$$
\begin{gathered}
\Pi_{d}=\max _{p_{d}}\left[w(1-\alpha)+\alpha p_{d}-c\right]\left(1-\frac{p_{d}+t}{\theta}\right) \\
\text { s.t. } p_{d} \geq \frac{(1-\theta+w) \theta}{2-\theta}-t .
\end{gathered}
$$


Also, using the Lagrangian duality to solve the above problems, we can get Proposition 3.

From Table 1, we easily know that $p_{d}^{S}$ is always decreasing in $t$; $p_{r}^{S}$ is increasing in $t$ when $t \leq t_{1}^{S}$ and $t \geq t_{2}^{S}$, but it does not have any relationship with $t$ when $t_{1}^{S} \leq t \leq t_{2}^{S}$.

4.2. Nash Equilibrium. In the Nash equilibrium version of the competition, the price decisions of two channels are assumed to be given simultaneously. Each player is assumed to know how the other would behave; there is no priority or time sequence among the players' decisions. Hence, the profits of retailer and manufacturer are

$$
\begin{aligned}
\Pi_{r}= & \max _{p_{r}}\left(p_{r}-w\right)(1-\alpha)\left(1-\frac{p_{r}-p_{d}-t}{1-\theta}\right), \\
\Pi_{d}= & \max _{p_{d}}\left[w(1-\alpha)+\alpha p_{d}\right]\left(1-\frac{p_{r}-p_{d}-t}{1-\theta}\right) \\
& -c\left(1-\frac{p_{d}+t}{\theta}\right) \\
& +\left[p_{d}(1-\beta)+l \beta\right]\left(\frac{p_{r}-p_{d}-t}{1-\theta}-\frac{p_{d}+t}{\theta}\right) \\
& \text { s.t. } p_{r} \geq \frac{p_{d}+t}{\theta} .
\end{aligned}
$$

Since each profit function is strictly concave, each player has a unique response for every decision of the competitor. Hence, we can get the following proposition.

Proposition 4. Under the decentralized dual-channel supply chain, there is a threshold delivery time

$$
\begin{aligned}
t^{N}=( & \alpha \theta^{3}-(1-\beta+c-w+3 \alpha w) \theta^{2} \\
& +(1-\alpha-\beta+3 c-w-\beta l+3 \alpha w-\beta w) \theta \\
& -2 c+2 l \beta)((2-\theta)(1-\alpha \theta-\beta))^{-1} .
\end{aligned}
$$

If $t>t^{N}$, the Nash equilibrium prices $\left(p_{d}^{N}, p_{r}^{N}\right)$ are

$$
\begin{aligned}
p_{d}^{N}= & \left((\beta-\alpha-1) \theta^{2}\right. \\
& +(1+\alpha+t+3 w+\alpha t-\beta t-3 \alpha w-\beta w-\beta-2 c) \theta \\
& +2 \beta t+2 c-2 t-2 l \beta) \\
& \times(4+\beta \theta-3 \alpha \theta-4 \beta-\theta)^{-1}, \\
p_{r}^{N}= & \left(\alpha \theta^{2}-(\alpha-2 \beta+c+2+\alpha t-w+3 \alpha w) \theta\right. \\
& +2+c+t+2 w-2 \beta-2 \beta w-l \beta-\beta t) \\
& \times(4+\beta \theta-3 \alpha \theta-4 \beta-\theta)^{-1} .
\end{aligned}
$$

(Case D1)
If $t \leq t^{N}$, the Nash equilibrium prices $\left(p_{d}^{N}, p_{r}^{N}\right)$ are

$$
\begin{aligned}
p_{d}^{N}=( & -\alpha \theta^{3}+(2 \alpha+w+\alpha t-c-1-\alpha w) \theta^{2} \\
& +(1+c+t+w-\alpha-l \beta-2 \alpha t-\alpha w) \theta+2 \alpha t-2 t) \\
& \times\left(2+2 \alpha \theta-2 \alpha-\beta \theta-2 \alpha \theta^{2}\right)^{-1}, \\
p_{r}^{N}= & \left(\left(\left(\frac{\beta}{2}+\alpha+w-c-\alpha t-\alpha w-1\right) \theta\right.\right. \\
& \quad+c+t+w-l \beta-\beta t-\alpha w) \\
& \left.\times\left(2+2 \alpha \theta-2 \alpha-\beta \theta-2 \alpha \theta^{2}\right)^{-1}\right)+\frac{1}{2} .
\end{aligned}
$$

(Case D2)

The Nash equilibrium policy is continuous at the threshold $t^{N}$.

Proof. The Lagrangian and the Karush-Kuhn-Tucker optimality conditions are

$$
\begin{gathered}
L\left(p_{r}\right)=\left(p_{r}-w\right)(1-\alpha)\left(1-\frac{p_{r}-p_{d}-t}{1-\theta}\right) \\
+\lambda\left(p_{r}-\frac{p_{d}+t}{\theta}\right), \\
L\left(p_{d}\right)=\left[w(1-\alpha)+\alpha p_{d}\right]\left(1-\frac{p_{r}-p_{d}-t}{1-\theta}\right) \\
-c\left(1-\frac{p_{d}+t}{\theta}\right)+\left[p_{d}(1-\beta)+l \beta\right] \\
\times\left(\frac{p_{r}-p_{d}-t}{1-\theta}-\frac{p_{d}+t}{\theta}\right)+\lambda\left(p_{r}-\frac{p_{d}+t}{\theta}\right), \\
\frac{\partial L\left(p_{r}\right)}{\partial p_{r}=}(1-\alpha)\left(1-\frac{2 p_{r}-p_{d}-t-w}{1-\theta}\right)+\lambda=0, \\
\frac{\partial L\left(p_{d}\right)}{\partial p_{d}}= \\
\begin{aligned}
& \alpha-\frac{2 p_{d}-c+t+\lambda+l \beta-2 \beta p_{d}-\beta t}{\theta} \\
&+\left(2 p_{d}-p_{r}+t-w+l \beta-2 \alpha p_{d}+\alpha p_{r}\right.
\end{aligned} \\
\left.\quad-2 \beta p_{d}+\beta p_{r}-\alpha t-\beta t+\alpha w\right) \\
\times(\theta-1)^{-1}=0, \\
\quad \lambda\left(p_{r}-\frac{p_{d}+t}{\theta}\right)=0 .
\end{gathered}
$$

Since the multiplier can be either zero or positive, we could have two cases to examine. Using the similar analysis of Proposition 1, we can get the result.

\section{Supply Chain Coordination}

From the above analysis, we can find that the prices of decentralized supply chain are different with the centralized supply 
chain. Hence, the total profit of decentralized supply chain is lower than the centralized supply chain. In this section, we will use resale price maintenance (RPM) to coordinate the supply chain. In an RPM $(w, p, Q)$ contract with quantity fixing, the manufacturer specifies a resale price for the retailer and controls the quantity of goods to be sold in the market [24].

Since the coordination policy can only be used in the Stackelberg game, in order to maximize the total supply chain profit, the manufacturer as the Stackelberg leader should let the prices $\left(p_{d}^{S}, p_{r}^{S}\right)$, equal to the centralized prices $\left(p_{d}^{*}, p_{r}^{*}\right)$. This coordination contract can be recognized as the RPM $\left(w, p_{d}^{*}, p_{r}^{*}\right)$ contract. But only the RPM $\left(w, p_{d}^{*}, p_{r}^{*}\right)$ contract may damage one player's profit and benefit the other. Hence, we will discuss the implementation of the contract $\left(w, p_{d}^{*}, p_{r}^{*}\right)$ with other complementary agreements between the manufacturer and the retailer that can coordinate the dual-channel supply chain and ensure a win-win for both players.

In this paper, we find that a two-part tariff agreement is a useful method to resolve this problem; that is, the retailer can charge a lump sum fee $(F)$ when it accepts the contract $\left(w, p_{d}^{*}, p_{r}^{*}\right)$. Hence, the contract $\left(w, p_{d}^{*}, p_{r}^{*}, F\right)$ can coordinate the dual-channel supply chain and enable both the retailer and the manufacturer to be a win-win, where $F$ satisfies $\Pi_{r}\left(p_{d}^{S}, p_{r}^{S}\right) \leq \Pi_{r}\left(p_{d}^{*}, p_{r}^{*}\right)+F$ and $\Pi_{d}\left(p_{d}^{S}, p_{r}^{S}\right) \leq \Pi_{d}\left(p_{d}^{*}, p_{r}^{*}\right)-F$, that is,

$$
F \in\left[\Pi_{r}\left(p_{d}^{S}, p_{r}^{S}\right)-\Pi_{r}\left(p_{d}^{*}, p_{r}^{*}\right), \Pi_{d}\left(p_{d}^{*}, p_{r}^{*}\right)-\Pi_{d}\left(p_{d}^{S}, p_{r}^{S}\right)\right] .
$$

Here, $F$ is positive if the contract $\left(w, p_{d}^{*}, p_{r}^{*}\right)$ damages the retailer's profit; $F$ is negative if the contract $\left(w, p_{d}^{*}, p_{r}^{*}\right)$ damages the manufacturer's profit.

We provide an example to illustrate how to use the coordination contract in practice. We use the same base numbers as the next section and let $t=0.1$. Then we have $\Pi_{r}\left(p_{d}^{S}, p_{r}^{S}\right)=0.0400, \Pi_{d}\left(p_{d}^{S}, p_{r}^{S}\right)=0.0450$ and $\Pi_{r}\left(p_{d}^{*}, p_{r}^{*}\right)=$ $0.0371, \Pi_{d}\left(p_{d}^{*}, p_{r}^{*}\right)=0.0644$. We can find that the $\left(w, p_{d}^{*}, p_{r}^{*}\right)$ enhances the retailer's profit and coordinates the supply chain but does not benefit the manufacturer. Hence, we use a complementary agreement $(F)$ to adjust the profit allocation and ensure a win-win for both the manufacturer and the retailer. Using (22) we can get the retailer to charge a lump sum fee $F \in$ $[0.0029,0.0194]$, so the contract $\left(w, p_{d}^{*}, p_{r}^{*}, F\right)$ can coordinate the dual-channel supply chain.

\section{Numerical Studies}

Our objective in this section is to gain further insights based on a numerical example. Also, in this section we only consider the scenario of $p_{r} \geq\left(p_{d}+t\right) / \theta$ in both centralized and decentralized supply chains. We use the following numbers as the base values of the parameters: $\alpha=0.2, \beta=0.25, l=0.2$, $c=0.3, \theta=0.9$, and $w=0.4$.

In centralized supply chain, we can get $t>t_{2}^{*}=-0.2061$. Hence, we know that the prices satisfy Case B1. Then we can get the optimal prices by changing the delivery time $t$. This can be shown in Figure 1.

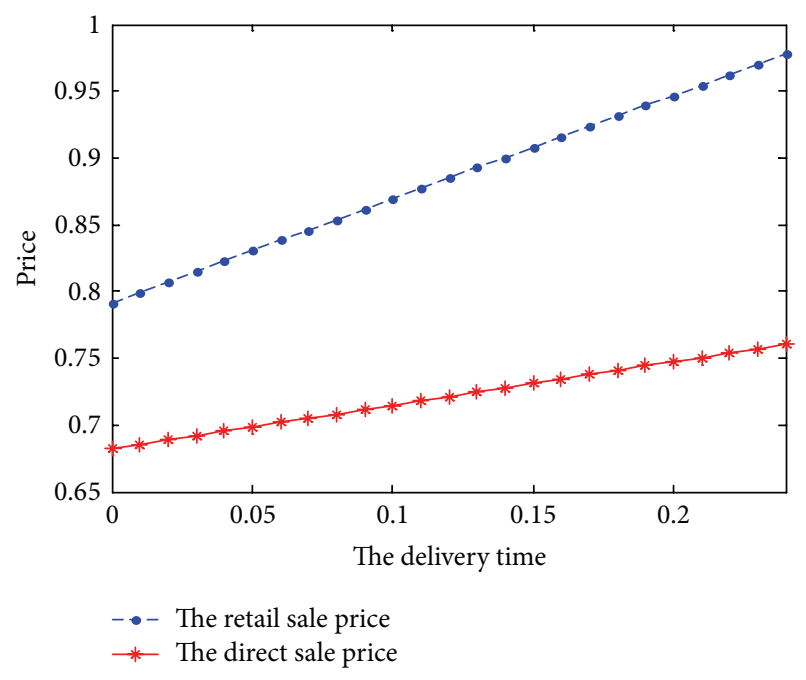

FIGURE 1: Effect of the delivery time on optimal prices of centralized supply chain.

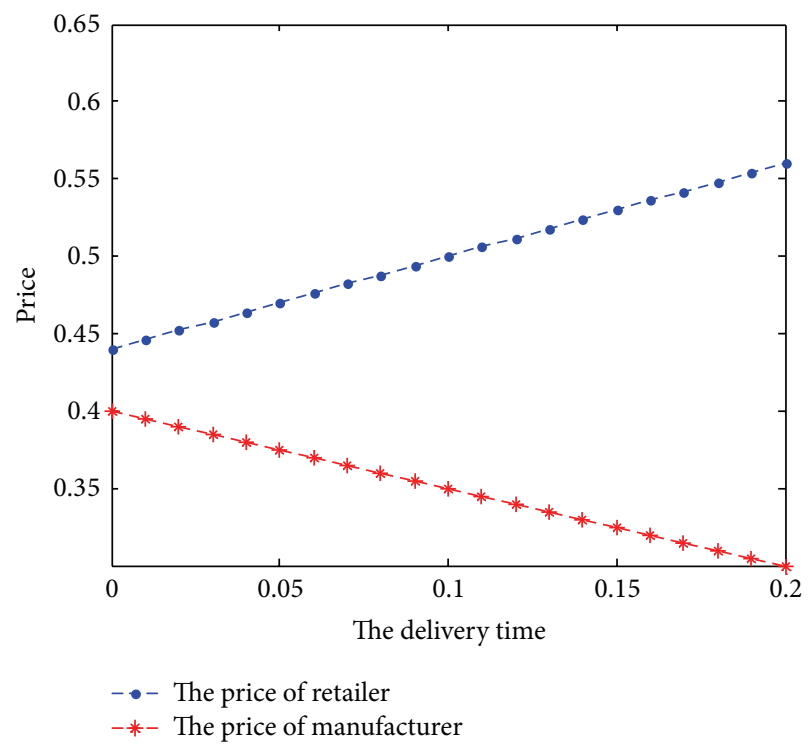

FIgURE 2: Effect of the delivery time on Stackelberg equilibrium prices.

Figure 1 indicates that the retail sale price is greater than the direct sale price under centralized supply chain. Since both prices are in $(0,1)$, we can get that the range of the delivery time is $(0,0.24)$. Also, we can find that the impact of delivery time on the direct sale price is less than on the retail sale price.

In Stackelberg game, similarly we can get the $t_{1}^{S}=-0.0575$ and $t_{2}^{S}=-0.0186$. Since $p_{d}>c=0.3$, we know that the range of $t$ should be $(0,0.2)$. Hence, we conclude that the Stackelberg equilibrium prices should satisfy Case C3. Then, we can draw the prices curves with the delivery time shown in Figure 2.

From Figure 2, we can see that $p_{d}^{S}$ is decreasing in $t$, while $p_{r}^{S}$ is increasing in $t$. This means that the manufacturer will 


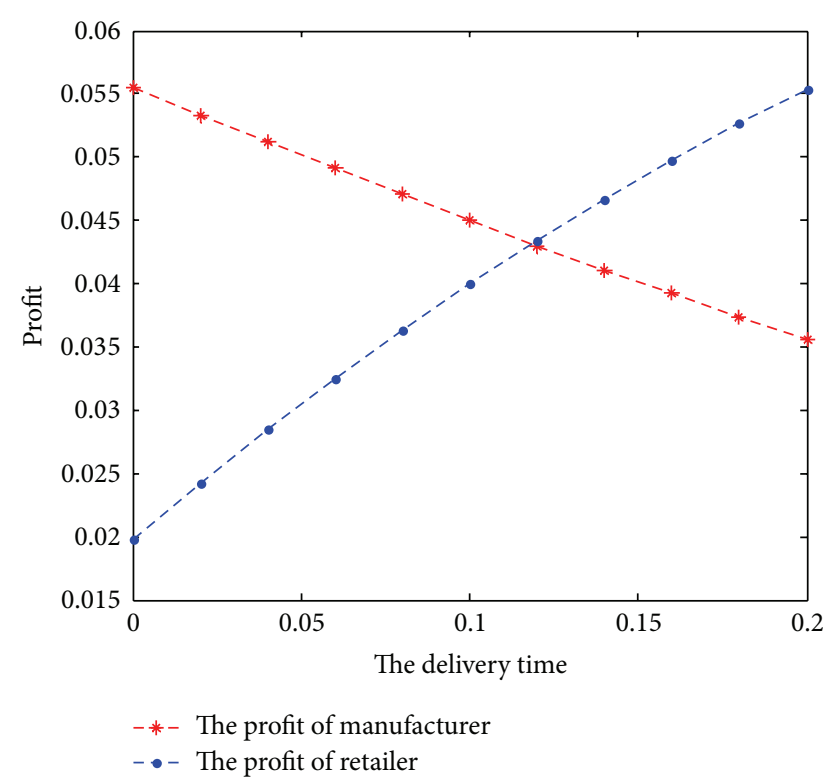

Figure 3: Effect of the delivery time on each player's profit under Stackelberg game.

have to decrease their direct sale price when their service level is low. This result is caused by the competition from the retailer.

Then, we can get Figure 3 which reflects how the delivery time affects each player's profit under Stackelberg game.

Figure 3 shows that the manufacturer's profit under Stackelberg game is decreasing in $t$, while the retailer's profit is increasing. Hence, under the Stackelberg game, the manufacturer should improve the service level and increase the direct sale price simultaneously to gain more profit.

In Nash equilibrium, we can get $t^{N}=-0.325$. Hence, we know that the Nash equilibrium prices satisfy Case D1. Then, we can get the relations of the Nash equilibrium prices and the delivery time shown in Figure 4.

Figure 4 shows that $p_{d}^{N}$ is decreasing in $t$, while $p_{r}^{N}$ is increasing in $t$. Since $p_{d}^{N}>c=0.3$, we can obtain that the valid range of $t$ is $(0,0.6)$. Then, we can get profit curves shown in Figure 5.

From Figure 5 we can find that both players' profits under Nash equilibrium are increasing in $t$. From intuition, the manufacturer's profit should decrease when the delivery time increases. However, we find that this intuition is wrong under Nash equilibrium. The main reason is that the source of manufacturer's profit is not only from the direct channel's customers but also from the retailer. Hence, when the delivery time increases, the decrement in direct channel can be offset by increased retailer's order quantity.

From the above analysis, we can find that $t \in(0,0.2)$ is the common valid range in modes of centralized supply chain, Stackelberg game, and Nash equilibrium. Hence, we will compare the profits under the range of $t \in(0,0.2)$. We use $\left(\Pi_{d}^{S}, \Pi_{r}^{S}\right)$ and $\left(\Pi_{d}^{N}, \Pi_{r}^{N}\right)$ to represent the manufacturer's profit and the retailer's profit under Stackelberg game and Nash equilibrium, respectively. Let $\Pi_{T}^{C}$ be the total supply chain's

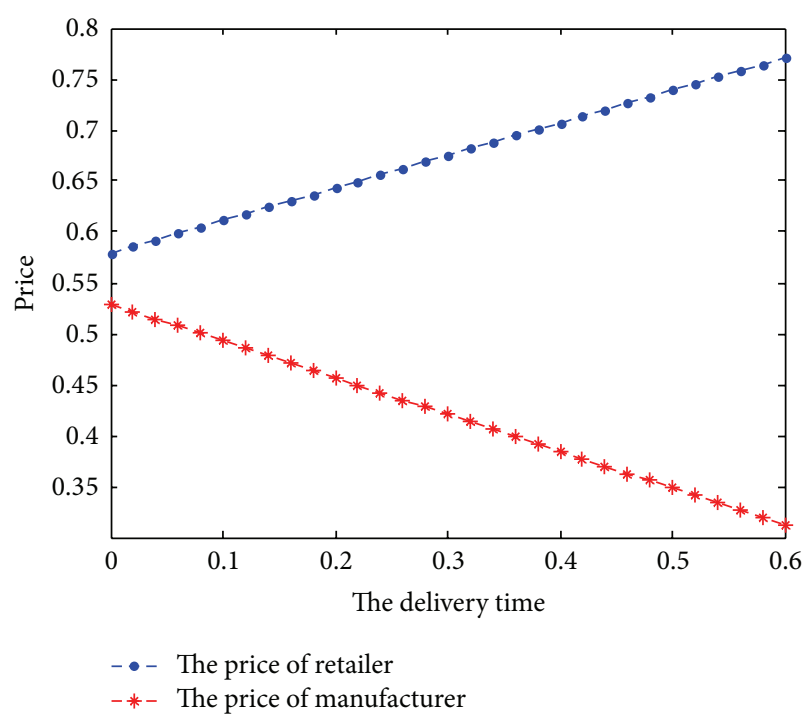

FIGURE 4: Effect of the delivery time on Nash equilibrium prices.

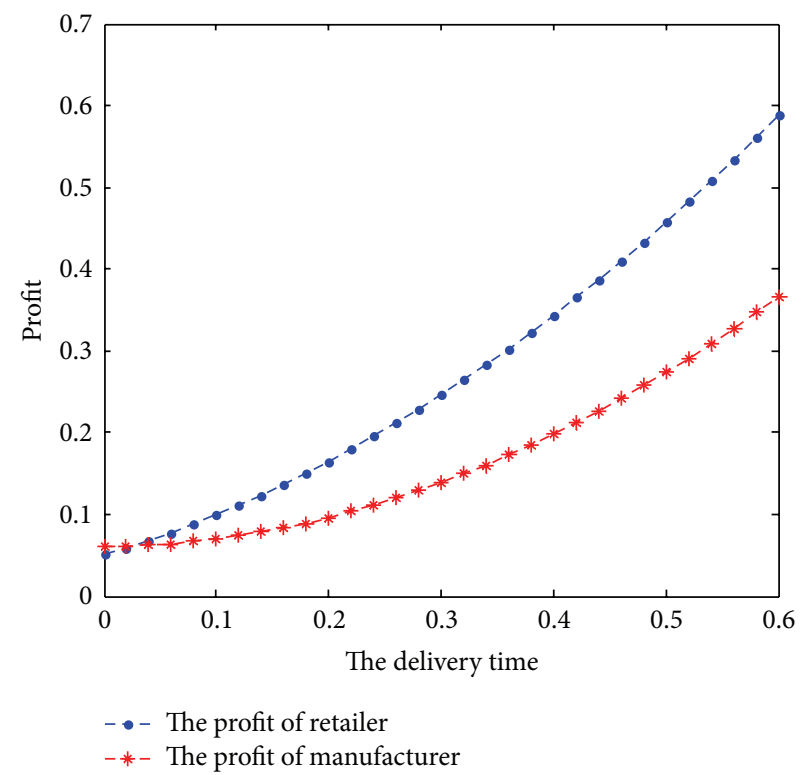

FIGURE 5: Effect of the delivery time on each player's profit under Nash equilibrium.

profit under centralized supply chain. Then, we can plot the profit gap between Nash equilibrium and Stackelberg game at the range of $t \in(0,0.2)$ in Figure 6.

Figure 6 shows that each player's profit under Nash equilibrium is higher than the one under Stackelberg game, and each player's profit gap between the two games is increasing in $t$.

Figure 7 depicts the total profits of supply chain under three modes with respect to $t$.

From Figure 7 we can find that the total supply chain's profit under centralized supply chain is larger than the decentralized modes, that is, Stackelberg game and Nash equilibrium. This will make it possible that the decentralized supply 


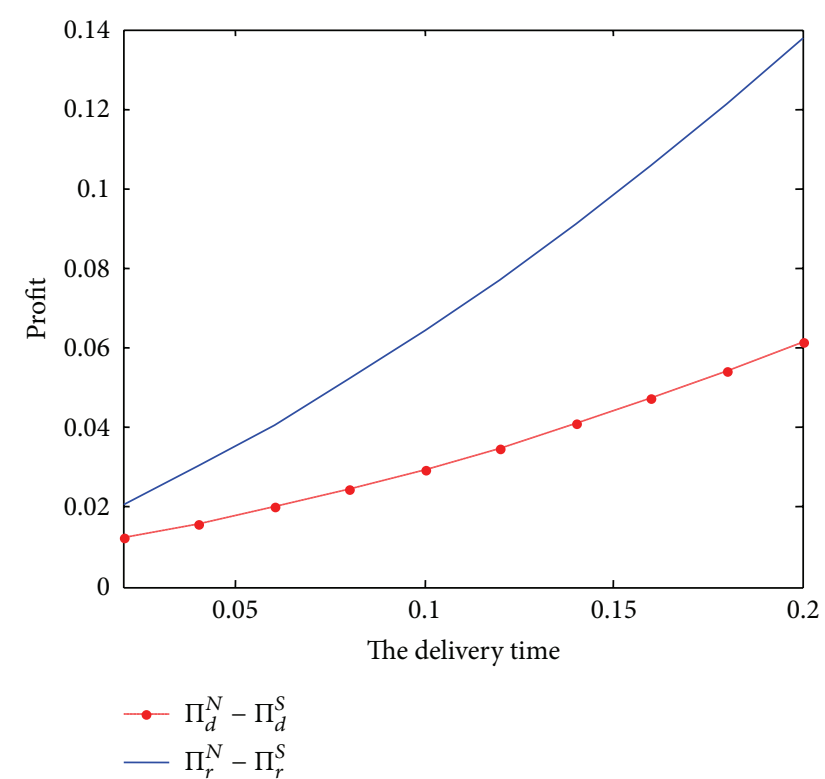

FIgURE 6: Profit gap between Nash equilibrium and Stackelberg game with the delivery time.

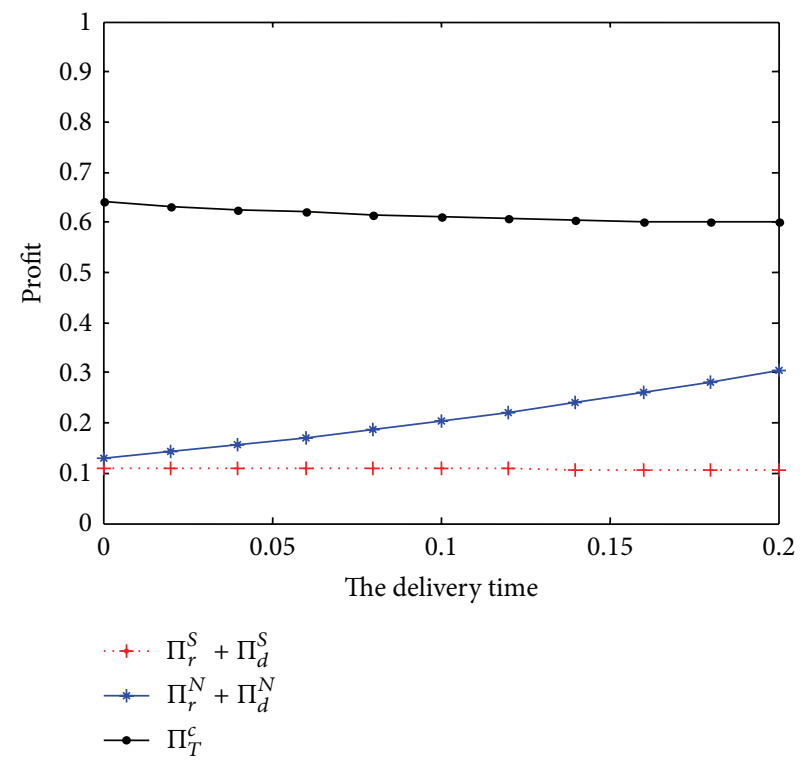

FIGURE 7: Total profits of three modes with respect to the delivery time.

chain can adopt the coordination contract $\left(w, p_{d}^{*}, p_{r}^{*}, F\right)$ to realize the win-win outcome. Also, we can see that the total profit under Nash equilibrium is bigger than the Stackelberg game.

\section{Conclusions}

Dual-channel supply chain with price and service competition is prevalent in reality. In this paper, considering there exists price and service competition between dual channels, we derive the equilibrium prices under centralized and decentralized supply chains with consumer returns. In decentralized supply chain, we consider the two different competition types, that is, Stackelberg game and Nash equilibrium. Since the total supply chain's profit under decentralized supply chain is less than the centralized supply chain, we put forward a new contract $\left(w, p_{d}^{*}, p_{r}^{*}, F\right)$ to coordinate the decentralized supply chain and gain the win-win outcome.

From numerical studies, we also find some interesting results. For instance, in some cases, both players can get more profit under Nash equilibrium than under the Stackelberg game. In addition, we can find that, under Nash equilibrium, prolonging the delivery time possibly becomes an effective measure to improve each player's profit.

There are several interesting topics for further research. For example, we can extend one retailer to multiple retailers. The competition between the multiple retailers will affect the decisions between channels. We plan to explore this issue in a future study.

\section{Conflict of Interests}

The authors declare that there is no conflict of interests regarding the publication of this paper.

\section{Acknowledgments}

This work is supported by the National Natural Science Foundation of China (nos. 71001025 and 71371003). Also, this research is partly supported by the Program for New Century Excellent Talents in University (no. NCET-10-0327) and the Ministry of Education of China: Grant-in-Aid for Humanity and Social Science Research (no. 11YJCZH139).

\section{References}

[1] J. Stock, T. Speh, and H. Shear, "Many happy (product) returns," Harvard Business Review, vol. 80, pp. 17-18, 2002.

[2] C. Lawton, “The war on returns," Wall Street Journal, 2008.

[3] L. Trager, "Not so many happy returns," Interactive Week, vol. 7, no. 11, pp. $44-45,2000$.

[4] D. S. Rogers and R. S. Tibben-Lemke, Going Backwards: Reverse Logistics Trends and Practices, Reverse Logistics Executive Council, Pittsburgh, Pa, USA, 1999.

[5] S. L. Wood, "Remote purchase environments: the influence of return policy leniency on two-stage decision processes," Journal of Marketing Research, vol. 38, no. 2, pp. 157-169, 2001.

[6] K.-Y. Chen, M. Kaya, and Ö. Özer, "Dual sales channel management with service competition," Manufacturing and Service Operations Management, vol. 10, no. 4, pp. 654-675, 2008.

[7] A. Dumrongsiri, M. Fan, A. Jain, and K. Moinzadeh, "A supply chain model with direct and retail channels," European Journal of Operational Research, vol. 187, no. 3, pp. 691-718, 2008.

[8] G. Hua, S. Wang, and T. C. E. Cheng, "Price and lead time decisions in dual-channel supply chains," European Journal of Operational Research, vol. 205, no. 1, pp. 113-126, 2010.

[9] G. Cai, Z. G. Zhang, and M. Zhang, "Game theoretical perspectives on dual-channel supply chain competition with price discounts and pricing schemes," International Journal of Production Economics, vol. 117, no. 1, pp. 80-96, 2009. 
[10] S.-H. Chun, B.-D. Rhee, S. Y. Park, and J.-C. Kim, "Emerging dual channel system and manufacturer's direct retail channel strategy," International Review of Economics and Finance, vol. 20, no. 4, pp. 812-825, 2011.

[11] B. Liu, R. Zhang, and M. Xiao, "Joint decision on production and pricing for online dual channel supply chain system," Applied Mathematical Modelling, vol. 34, no. 12, pp. 4208-4218, 2010.

[12] J. Chen and P. C. Bell, "Implementing market segmentation using full-refund and no-refund customer returns policies in a dual-channel supply chain structure," International Journal of Production Economics, vol. 136, no. 1, pp. 56-66, 2012.

[13] S. Huang, C. Yang, and X. Zhang, "Pricing and production decisions in dual-channel supply chains with demand disruptions," Computers and Industrial Engineering, vol. 62, no. 1, pp. 70-83, 2012.

[14] M. A. Lariviere and E. L. Porteus, "Selling to the newsvendor: an analysis of price-only contracts," Manufacturing and Service Operations Management, vol. 3, no. 4, pp. 293-305, 2001.

[15] B. Pasternack, "Optimal pricing and returns policies for perishable commodities," Marketing Science, vol. 4, pp. 166-176, 1985.

[16] Y. He, X. Zhao, L. Zhao, and J. He, "Coordinating a supply chain with effort and price dependent stochastic demand," Applied Mathematical Modelling, vol. 33, no. 6, pp. 2777-2790, 2009.

[17] J. Chen and P. C. Bell, "Coordinating a decentralized supply chain with customer returns and price-dependent stochastic demand using a buyback policy," European Journal of Operational Research, vol. 212, no. 2, pp. 293-300, 2011.

[18] Y. He and X. Zhao, "Coordination in multi-echelon supply chain under supply and demand uncertainty," International Journal of Production Economics, vol. 139, pp. 106-115, 2012.

[19] G. P. Cachon, "Supply chain coordination with contracts," in Handbooks in OR and MS, A. G. de Kok and S. C. Graves, Eds., vol. 11, pp. 229-339, Elesiver Science, North-Holland, Amsterdam, The Netherlands, 2003.

[20] A. Arshinder, A. Kanda, and S. G. Deshmukh, "Supply chain coordination: perspectives, empirical studies and research directions," International Journal of Production Economics, vol. 115, no. 2, pp. 316-335, 2008.

[21] G. Cai, "Channel selection and coordination in dual-channel supply chains," Journal of Retailing, vol. 86, no. 1, pp. 22-36, 2010.

[22] J. Chen, H. Zhang, and Y. Sun, "Implementing coordination contracts in a manufacturer Stackelberg dual-channel supply chain," Omega, vol. 40, no. 5, pp. 571-583, 2012.

[23] W.-Y. K. Chiang, D. Chhajed, and J. D. Hess, "Direct marketing, indirect profits: a strategic analysis of dual-channel supplychain design," Management Science, vol. 49, no. 1, pp. 1-20, 2003.

[24] H. Gurnani and Y. Xu, "Resale price maintenance contracts with retailer sales effort: effect of flexibility and competition," Naval Research Logistics, vol. 53, no. 5, pp. 448-463, 2006. 


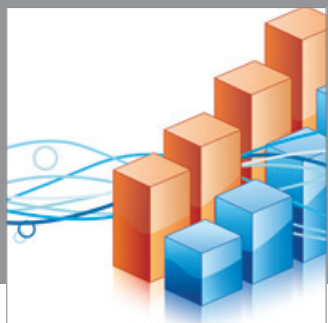

Advances in

Operations Research

mansans

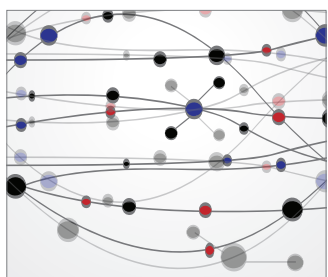

The Scientific World Journal
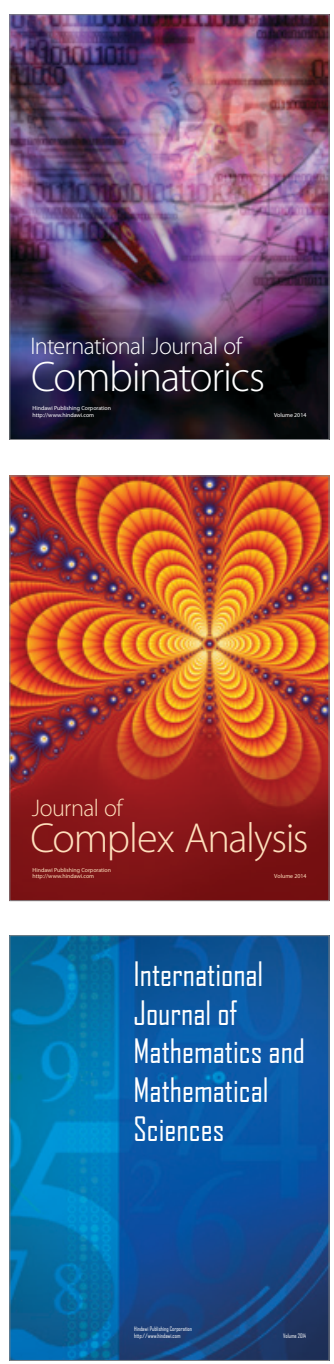
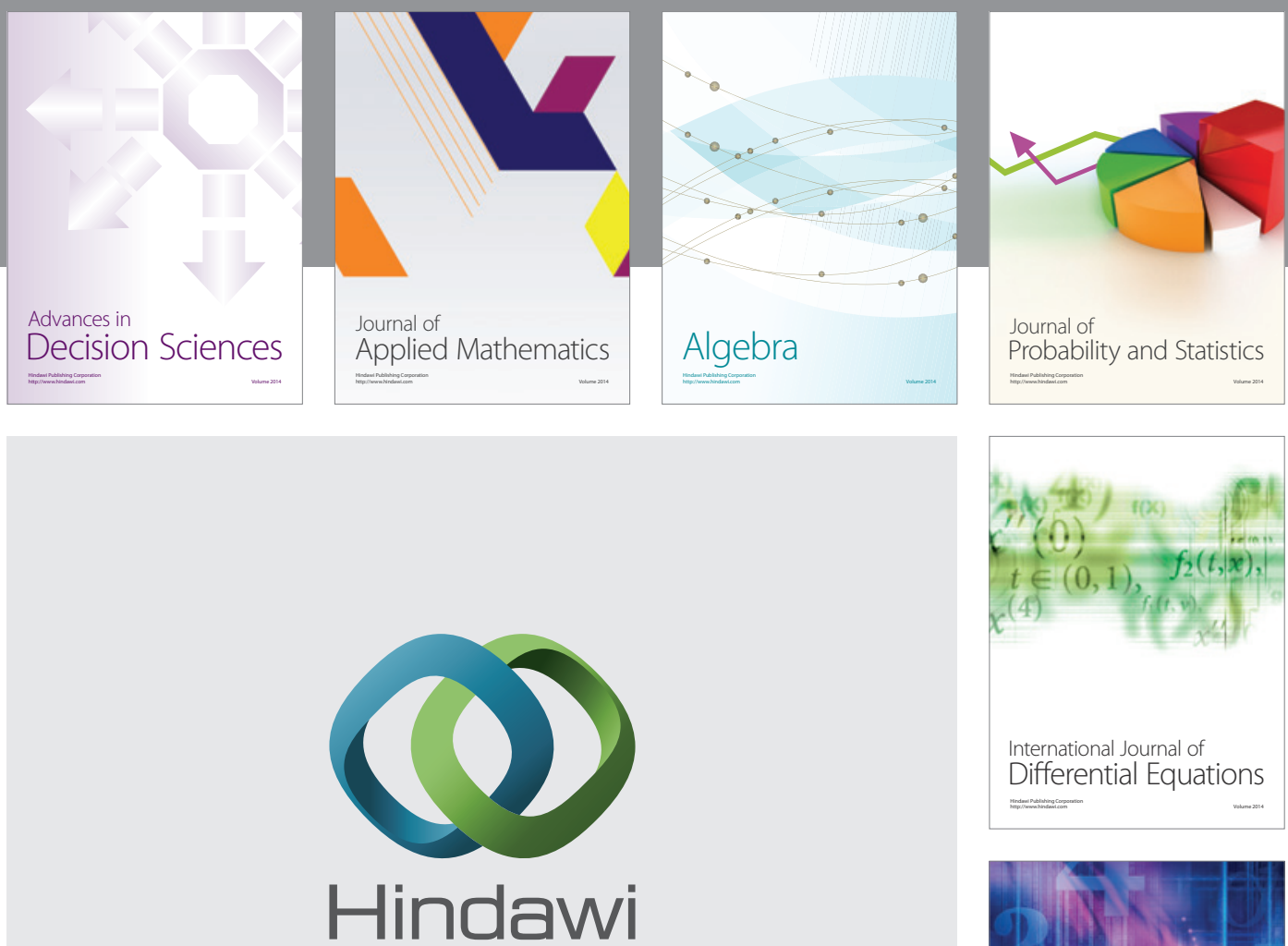

Submit your manuscripts at http://www.hindawi.com
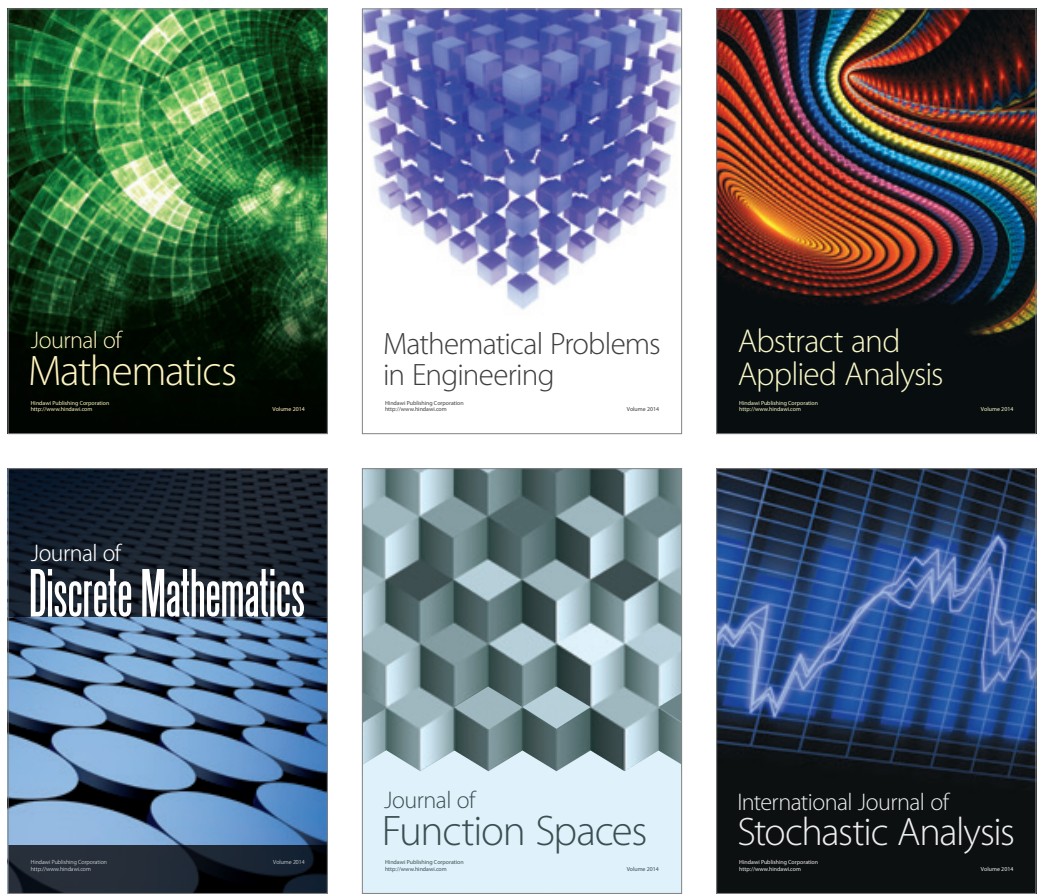

Journal of

Function Spaces

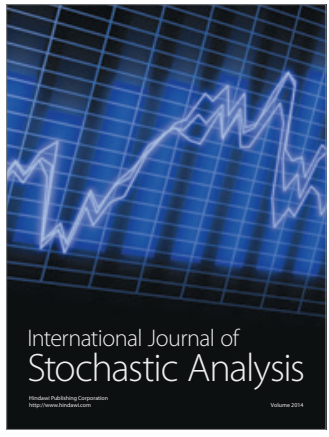

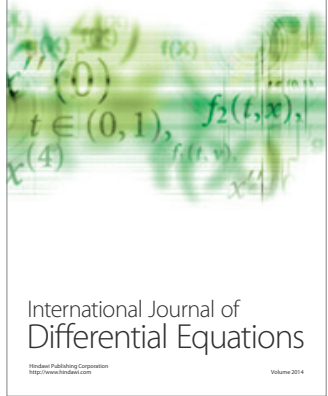
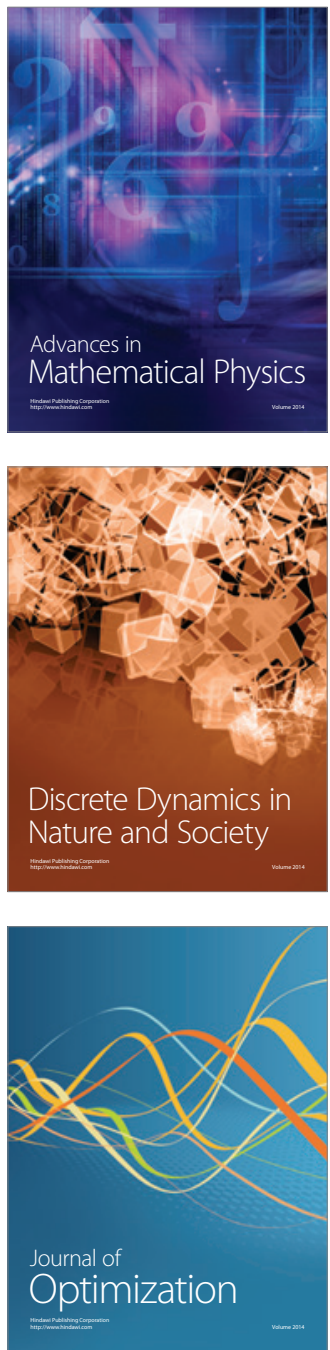